\title{
PENERAPAN KESELAMATAN DAN KESEHATAN KERJA BALAWISTA DI PANTAI KUTA
}

Satwika Wiguna Kusumaa,1, Ida Bagus Suryawana,2

${ }^{1}$ satwika24@yahoo.com, 2inigusmail@yahoo.com

a Program Studi S1 Destinasi Pariwisata, Fakultas Pariwisata,Universitas Udayana, Jl. Dr. R. Goris, Denpasar, Bali 80232 Indonesia

\begin{abstract}
Kuta beach is one of the most visited places in Bali, it offer a great beach with a perfect wave to surf and become a number one spot for any tourist who come to Bali for surfing. With that being said the accident rate of water related accident in the area is very high, to manage the risk and ensuring the safety of the area Gede Berata a Balinese partnering with two Australian Kevin Weldon and Alan B Welpton founding The Indonesian Surf Life Saving Association/Badan Penyelamat Wisata Tirta or more known as Balawista.

This job require a very high standard of commitment, not only a competent staff but also need a sufficient equipment to help the rescue activity, it also require a high standard of operation procedure to ensure that the rescue are done in a safe and efficient manner to ensure the safety for both of the victims and rescuers. The goals of this research are to know how far Balawista implement health and safety procedure when doing daily operation, and what are the other factors that impacting the performance of Balawista. The data are collected using an observation method and in-depth interview and using purpose sampling method, data analytic method using qualitative descriptive.

With this paper writer hope that Balawista will be able to do their job professionally by implementing health and safety procedure considering the high importance of their job and by doing that they will be able to increase the safety for both of the victims and rescuers.
\end{abstract}

Keywords: Balawista, Health and Safety, Occupational Accidents

\section{PENDAHULUAN}

\subsection{Latar Belakang}

Bali sebagai salah satu daerah tujuan wisata, mempunyai potensi alam yang mampu menarik minat wisatawan untuk mengunjungi Bali. Salah satu dari sekian banyak potensi alam tersebut adalah Pantai Kuta. Pantai Kuta yang terletak di wilayah Badung bagian selatan merupakan salah satu pantai yang ramai dikunjungi oleh wisatawan karena memiliki panorama yang indah seperti pasir pantai yang putih bersih, pemandangan matahari terbenam (sunset) serta ombak nya sangat cocok untuk melakukan aktifitas surfing. Seiring dengan banyaknya kunjungan wisatawan yang mengunjungi Pantai Kuta, maka aktivitas yang dilakukan oleh wisatawan juga semakin meningkat. Tingginya aktivitas wisatawan membuat potensi terjadinya kecelakaan saat beraktivitas di Pantai Kuta juga tinggi. Seperti yang tertara dalam table berikut, dimana tercatat 5 kasus kecelakaan wisatawan saat beraktivitas di Pantai Kuta yang berhasil ditangani balawista pada tahun 2013. Dimana 4 diantaranya berhasil diselamatkan dan 1 orang meninggal dunia.
Table 1. Penanganan Balawista terhadap kecelakaan di Pantai Kuta tahun 2013

\begin{tabular}{|c|c|c|c|c|}
\hline No & Nama & Kasus & Asal & Keterangan \\
\hline 1 & Deni & $\begin{array}{c}\text { Terseret } \\
\text { ombak }\end{array}$ & Indonesia & Selamat \\
\hline 2 & $\begin{array}{c}\text { Fernandes } \\
\text { Hugo }\end{array}$ & $\begin{array}{c}\text { Terseret } \\
\text { ombak }\end{array}$ & Spanyol & Selamat \\
\hline 3 & $\begin{array}{c}\text { Frolence } \\
\text { Allen }\end{array}$ & $\begin{array}{c}\text { Kecelakaan } \\
\text { saat surfing }\end{array}$ & Inggris & Selamat \\
\hline 4 & Zhoug Jingbin & $\begin{array}{c}\text { Kecelakaan } \\
\text { saat surfing }\end{array}$ & Cina & Selamat \\
\hline 5 & $\begin{array}{c}\text { Andreas } \\
\text { Essen }\end{array}$ & $\begin{array}{c}\text { Serangan } \\
\text { jantung saat } \\
\text { di pantai }\end{array}$ & Jerman & Meninggal \\
\hline
\end{tabular}

Sumber : Badan Penyelamat Wisata Tirta Badung, 2013

Kunci sukses sebuah kegiatan pariwisata harus memperhatikan safety and security (kenyamanan dan keamanan). Dalam mendukung kegiatan pariwisata Bali maka dibutuhkan usaha untuk menangani kecelakaan kegiatan wisatawan di Pantai Kuta. Untuk menanggulanginya, maka Gede Berata bersama dengan 2 orang asing berkewarganegaraan Australia yaitu Mr. Kevin Weldon dan Mr. Alan B Whelpton membentuk sebuah badan penyelamat wisata tirta atau yang hingga saat ini disebut balawista. Keberadaan balawista adalah sebagai aparat penyelamat di pantai. Badan penyelamat wisata tirta memberikan pelayanan kepada siapapun yang ada di Pantai Kuta artinya tidak melihat strata sosialnya, 
tingkat pendidikannya, pekerjaan , wisatawan lokal atau wisatawan mancanegara.

Tujuan dari penelitian ini untuk mengetahui sejauh mana balawisata sudah menerapkan keselamatan dan kesehatan kerja di lapangan dan untuk mengetahui faktor faktor yang mempengaruhi beban kerja balawista. Penelitian ini penting dilakukan karena pekerjaan yang mereka lakukan menyangkut keselamatan wisatawan serta balawisata itu sendiri saat bertugas

\subsection{Rumusan Masalah}

Berdasarkan latar belakang diatas, maka rumusan masalah yang diangkat adalah :

1. Bagaimanakah penerpan keselamatan dan kesehatan kerja balawista di Pantai Kuta?

2. Faktor - faktor apa sajakah mempengaruhi beban kerja balawisata saat di Pantai Kuta?

\section{KEPUSTAKAAN}

\subsection{Tinjauan Penelitian Sebelumnya}

Terdapat dua hasil laporan akhir yang terkait dalam menunjang penelitian ini. Pertama adalah laporan akhir yang ditulis Asri Karima ( 2014 ) dengan judul Faktor - Faktor Yang Berhubungan Dengan Stress Kerja Pada Pekerja Di PT X Tahun 2014. Penelitian ini memiliki kesamaan fokus, dimana penelitian ini membahas faktor faktor yang mempengaruhi beban kerja pekerja di lapangan di lapangan. Selanjutnya hasil laporan akhir yang ditulis Satvika Kurushottama ( 2004 ) dengan judul Peranan Badan Penyelamat Wisata Air ( Balawista J Dalam Meningkatkan Keamanan dan Keselamatan Wisatawan Yang Beraktivitas Di Pantai Kuta. Terdapat kesamaan fokus dan lokus dalam penelitian ini, yaitu fokus penelitian ini adalah pada cara kerja balawisata termasuk perawatan serta penggunaan alat penunjang kerja. Sedangkan kesamaan lokus penelitian ini adalah pengambilan tempat penelitian di Pantai Kuta.

\subsection{Landasan Konsep}

Penelitian ini menggunakan konsep dari Usman (2001) tentang penerapan, konsep dari Sudiara dan Sukana (2004) tentang keselamatan kerja dan kesehatan kerja, konsep dari Manuaba (2000) tentang beban kerja, dan konsep dari Ermawan Sutanto (2009) tentang balawisata.

\section{METODE PENELITIAN}

\subsection{Lokasi Penelitian}

Lokasi penelitian ini adalah di pos balawista di Pantai Kuta. Tempat ini terletak di Kabupaten Badung bagian selatan, berjarak sekitar $25 \mathrm{~km}$ bila ditempuh dari Kota Denpasar dengan perjalanan selama 30 Menit.

\subsection{Ruang Lingkup Penelitian}

Untuk memberikan batasan pada penelitian serta memperjelas masalah yang hendak dibahas, maka diperlukan ruang lingkup penelitian dalam penelitian ini, yaitu :

a. Penerapan penggunaan alat perlengkapan penunjang keselamatan dan kesehatan kerja balawisata di lapangan

b. Faktor - faktor yang mempengaruhi beban kerja balawisata di lapangan, yaitu faktor eksternal berasal dari luar tubuh balawista dan faktor internal yang berasal dari diri balawista.

\subsection{Jenis dan Sumber Data}

Penelitian ini menggunakan dua jenis data yaitu data kualitatif dari pendapat Strauss dan Korbin (2003) dan data kuantitatif dari pendapat Muslich (2010). Sedangkan sumber data penelitian ini yaitu sumber data primer yang dikemukakan oleh Umar (2003) dan data sekunder yang dikemukakan oleh kusmayadi (2000). Untuk teknik pengumpulan data, penelitian ini menggunakan 3 teknik pengumpulan data. Yaitu teknik observasi dan wawancara dari Moleong (2004), serta teknik studi kepustakaan dari Namawi (1995). Teknik penentuan informan dalam penelitian ini mengunakan teknik purposive sampling dari Mukhtar (2013) . Sedangkan untuk analisis data dalam penelitian ini menggunakan analisi data deskriptif kualitatif. Moleong (2004)

\section{HASIL DAN PEMBAHASAN}

\subsection{Gambaran Umum Balawista}

Keberadaan Balawista di Kuta Bali yang berdiri sejak 1972 ini sangat penting. Kehadirannya amat dibutuhkan untuk memberikan pertolongan kepada wisatawan yang tenggelam atau terseret arus. Balawista saat ini sudah mempunyai sekitar 170 anggota yang tersebar di 16 pos tersebar di Kabupaten Badung. Sedangkan untuk daerah Pantai Kuta sendiri terdiri dari 4 pos, yaitu di Pantai Kuta, Pantai Half Way, Pantai Depan Kamasutra, dan Pantai Legian. Dimana setiap pos terdiri dari 7 
anggota yang dibagi menjadi 2 shif yaitu shif pagi dengan 2 anggota yang berjaga sedangkan shif sore dengan 5 orang anggota yang berjaga setiap hari berpatroli untuk mengawasi wisatawan yang beraktifitas di pantai.

\subsection{Penerapan keselamatan dan kesehatan kerja balawista di Pantai Kuta}

Anggota balawista atau yang sering disebut lifeguard harus bisa mempersiapkan diri sebelum terjun ke lapangan, yaitu terkait penerapan kesehatan dan keselamatan kerja diri mereka sendiri. Kesehatan dan keselamatan kerja balawista ini berupa alat untuk membantu menunjang tugas balawista di lapangan. Adapun beberapa alat standart pengamanan yang harus digunakan anggota balawista untuk melakukan pengawasan, seperti gambar dibawah ini :

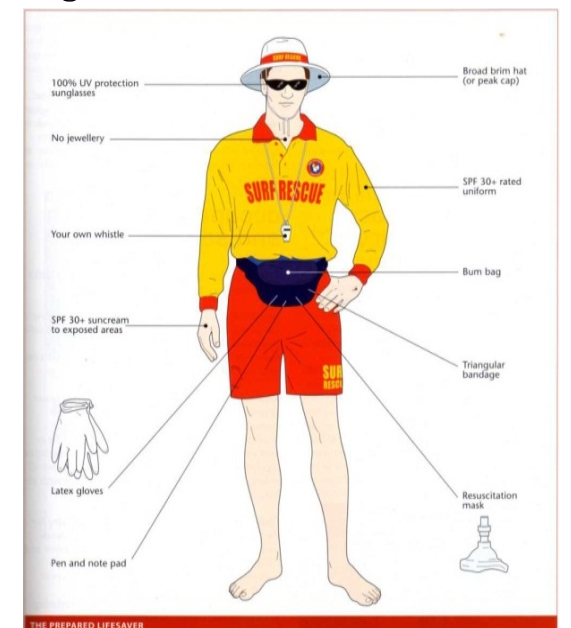

Gambar 1. Perlengkapan keselamatan kerja balawista Sumber: Badan Penyelamat Wisata Tirta Badung, 2013

Adapun alat standar yang digunakan balawista saat bertugas di lapangan sesuai dengan gambar diatas yaitu : topi, kacamata hitam, baju lengan panjang, peluit, tas pinggang, teropong, sarung tangan, pulpen \& buku kecil, dan masker keselamatan. Semua alat bantu kerja tersebut memiliki fungsi masing - masing sehingga sangat penting bagi balawista untuk selalu memakai peralatan tersebut saat bertugas. Adapaun Penerapan pemakaian alat bantu kerja keselamatan dan kesehatan kerja balawista berdasarkan pengamatan peneliti di lapangan, dapat dilihat dalam table berikut:
Tabel 2. Penerapan pemakaian alat bantu kerja keselamatan dan kesehatan kerja

\begin{tabular}{|c|c|c|c|}
\hline \multirow{2}{*}{ No } & Perlengkapan & \multicolumn{2}{|c|}{ Penerapan } \\
\cline { 3 - 4 } & $\begin{array}{c}\text { Sudah } \\
\text { diterap } \\
\text { kan }\end{array}$ & $\begin{array}{c}\text { Belum } \\
\text { diterap } \\
\text { kan }\end{array}$ \\
\hline $\mathbf{1}$ & Topi & $\checkmark$ & \\
\hline $\mathbf{2}$ & Kacamata hitam & $\checkmark$ & \\
\hline $\mathbf{3}$ & $\begin{array}{c}\text { Baju lengan } \\
\text { panjang }\end{array}$ & $\checkmark$ & \\
\hline $\mathbf{4}$ & Peluit & $\checkmark$ & \\
\hline $\mathbf{5}$ & $\begin{array}{c}\text { Tas Pinggang } \\
\mathbf{6}\end{array}$ & $\checkmark$ & \\
\hline $\mathbf{9}$ & Teropong & $\checkmark$ & \\
\hline $\mathbf{8}$ & $\begin{array}{c}\text { Sarung tangan } \\
\text { keselamatan }\end{array}$ & $\checkmark$ & \\
\hline $\mathbf{9}$ & $\begin{array}{c}\text { Masker } \\
\text { kalpen \&uku }\end{array}$ & $\checkmark$ & \\
\hline
\end{tabular}

Sumber : Data diolah dari hasil penelitian, 2014

Dari hasil pengamatan di lapangan, balawista di Pantai Kuta sudah memenuhi standart penerapan perlengkapan kesehatan dan keselamatan kerja. Semua alat perlengkapan sudah stand by di badan setiap anggota balawista dan siap digunakan bila sewaktu waktu diperlukan dalam menjalankan tugasnya.

\subsection{Faktor - faktor yang mempengaruhi beban kerja balawista di Pantai Kuta a. Faktor eksternal}

Salah faktor eksternal dalam pengaruh beban kerja balawista adalah pengaruh lingkungan kerja. Ada lima faktor yang mempengaruhi lingkungan kerja terhadap beban kerja balawista, faktor fisik, kimia, biologi, fisiologi dan psikologi. Berikut tabel penilaian pengaruh lingkungan kerja terhadap beban kerja balawista: 
Tabel 3. Penilaian Pengaruh Lingkungan Kerja Terhadap Beban Kerja Balawista di Pantai Kuta

\begin{tabular}{|c|c|c|c|c|}
\hline Faktor & Indikator & Kondisi riil & Kondisi di lapangan & Penilaian \\
\hline Fisik & $\begin{array}{l}\text { Penerangan, } \\
\text { Suhu, } \\
\text { Kelembapan }\end{array}$ & $\begin{array}{c}\text { Suhu yang stabil } \\
\text { kan membantu } \\
\text { kinerja di lapangan }\end{array}$ & $\begin{array}{c}\text { Suhu di Pantai Kuta sangat } \\
\text { panas, dan cuaca yang } \\
\text { sangat terik }\end{array}$ & $\begin{array}{c}\text { Suhu yang panas membuat } \\
\text { kondisi fisik balawista cepat } \\
\text { terkuras }\end{array}$ \\
\hline Kimia & Gas ,Uap, Debu & $\begin{array}{c}\text { Bahan - bahan } \\
\text { kimia seharusnya } \\
\text { ditangani dengan } \\
\text { tindakan khusus. }\end{array}$ & $\begin{array}{l}\text { Sangat jarang ditemui zat } \\
\text { - zat kimia yang bersiko } \\
\text { mengancam keselantan } \\
\text { wisatwan }\end{array}$ & $\begin{array}{c}\text { Balawista tetap waspada } \\
\text { terhadap zat kimia yang } \\
\text { mungkin datang dari sampah } \\
\text { maupun limbah hotel }\end{array}$ \\
\hline Biologi & $\begin{array}{l}\text { Tumbuhan, } \\
\text { Hewan }\end{array}$ & $\begin{array}{c}\text { Hewan maupun } \\
\text { tanaman harus } \\
\text { dijaga agar tidak } \\
\text { menggangu pada } \\
\text { saat bekerja }\end{array}$ & $\begin{array}{c}\text { Sangat jarang ditemui } \\
\text { hewan maupun tumbuhan } \\
\text { yang mengancam } \\
\text { keselamatan wisatawan }\end{array}$ & $\begin{array}{c}\text { Balawista tetap mengawasi } \\
\text { apabila ada hewan maupun } \\
\text { tumbuhan yang mengancam } \\
\text { keselamatan wisatawan }\end{array}$ \\
\hline Fisiologi & $\begin{array}{l}\text { Kondisi mesin, } \\
\text { sikap, cara kerja }\end{array}$ & $\begin{array}{l}\text { Kondisi mesin yang } \\
\text { baik, harus } \\
\text { dibarengi oleh } \\
\text { perawatan yang } \\
\text { berkala. }\end{array}$ & $\begin{array}{c}\text { Alat bantu kerja balawista } \\
\text { masih sangat bagus dan } \\
\text { terjaga kondisinya }\end{array}$ & $\begin{array}{l}\text { Alat bantu balawista sangat } \\
\text { siap digunakan, selain itu } \\
\text { balawista secara berkala } \\
\text { merawat alat bantu tersebut }\end{array}$ \\
\hline Psikologis & $\begin{array}{c}\text { Suasana kerja, } \\
\text { hubungan antar } \\
\text { pekerja }\end{array}$ & $\begin{array}{l}\text { Hubungan antara } \\
\text { setiap pekerja harus } \\
\text { terjaga untuk } \\
\text { menunjang kinerja. }\end{array}$ & $\begin{array}{c}\text { Hubungan antar pekerja } \\
\text { balawista di Pantai Kuta } \\
\text { cukup baik karena interksi } \\
\text { setiap saat. }\end{array}$ & $\begin{array}{c}\text { Komunikasi balawista sangat } \\
\text { bagus, baik dengan sesame } \\
\text { balawista maupun } \\
\text { wisatawan. }\end{array}$ \\
\hline
\end{tabular}

Sumber : Data diolah dari hasil penelitian, 2014

Dari hasil penilaian diatas bisa diuraikan bahwa faktor lingkungan kerja sangat berpengaruh terhadap beban kerja balawista di Pantai Kuta, salah satunya faktor fisik yang indikatornya berupa suhu. Suhu yang panas dan terik membuat fisik balawista mudah terkuras saat menjalan tugas di Pantai Kuta.

Sedangkan faktor alam juga merupakan faktor eksternal salah yang termasuk mempengaruhi beban kerja balawista di Pantai Kuta. Faktor alam di sini sangat berbahaya meskipun sudah dapat diprediksi sebelumnya Sesuai dengan pendapat dari Bapak I Ketut Ipel selaku koordinator balawista Badung

"Waktu itu saya melakukan penyelamatan pada tahun 1988, ombak besar dan arus keras, kita sudah tahu, tapi namanya faktor alam, rasa takut itu ada dan kita harus tetap berusaha tenang. Tetapi kita kadang merasa was was juga karena kemepuan kita terbatas dan alat alat tidak secanggih sekarang, benar benar fisik yang kita pakai waktu itu".

(Wawancara pada 5 juni 2014)

\section{b. Faktor Internal}

Salah satu faktor Internal yang mempengaruhi beban kerja balawista adalah cara kerja atau etos kerja balawista. Beberapa balawista yang tidak fokus dan terkesan tidak serius dalam melakukan tugas. Seperti adanya anggota balawista yang menegak minuman keras seperti bir bersama wisatawan saat bertugas. Ini tentu sangat membahayakan diri sendiri maupun wisatawan yang akan ditolong bila sewaktu waktu diperlukan, karena balawista dituntut untuk sigap bila terjadi terjadi insiden yang menimpa wisatawan di Pantai Kuta. Meskipun dalam hal ini, balawista meminum bir dikarenakan untuk mengeratkan hubunganan antara anggota balawista dengan wisatawan dan menumbuhkan citra friendly di mata wisatawan.

\section{PENUTUP}

Penerapan keselamatan dan kesehatan balawista berupa penggunaan alat bantu kerja sudah sesuai standar yang ditentukan. Segala alat perlengakapan sudah stand by digunakan bila sewaktu waktu terjadi insiden yang menimpa wisatawan. Selain terdapat dua faktor 
yang mempengaruhi beban kerja balawista di Pantai Kuta yaitu faktor eksternal yang meliputi faktor lingkungan kerja dan faktor alam dan faktor internal yang meliputicara kerja balawista. Untuk penilaian pengaruh faktor lingkungan kerja dan faktor alam terhadap beban kerja balawista di Pantai Kuta, bisa disimpulkan bahwa pengaruh beban kerja sangat mempengaruhi kinerja anggota balawista dalam bertugas. Sedangkan untuk faktor internal yang mempengaruhi beban kerja balawista adalah cara kerja balawista di lapangan, dalam penelitian ini masih terdapat

\section{DAFTAR PUSTAKA}

Karima, Asri. (2014) . Faktor-Faktor Yang Berhubungan Dengan Stress Kerja Pada Pekerja Di PT X Tahun 2014. Skripsi. Fakultas Kedoktera dan Ilmu Kesehatan : Universitas Islam Negeri Syarif Hidayatullah.

Kusmayadi dan Sugiarto, Endar. (2000). Metode Penelitian dalam Bidang Kepariwisataan, Jakarta. Jakarta: PT Gramedia Pusataka Utama.

Kurushottama ,Satvika. (2004). Peranan Badan Penyelamat Wisata Air (Balawista) Dalam Meningkatkan Keamanan Dan Keselamatan Wisatawan Yang Beraktivitas Di Pantai Kuta. Skripsi. Fakultas Pariwisata : Universitas Udayana.

Koentjaningrat. (1997). Metode - Metode Penelitian Masyarakat. Jakarta: PT.Gramedia Pusaka Utama.

Manuaba, A. (2000). Ergonomi, Kesehatan dan Keselamatan Kerja. Surabaya : PT.Guna Widya

Mokhtar. (2013). Metode Praktis Penelitian Deskritif Kualitatif. Jakarta : REFRENSI ( GP Press Group )

Muslich. (2010). Metode Pengambilan Keputusan Kuantitatif. Jakarta : Bumi aksara

Moleong, L.J. (2004). Metode Penelitian Kualitatif. Bandung :PT. Remaja Rodakarya.

Namawi, H. Hadiri. (1995). Metode Penelitian Bidang Sosial. Yogyakarta: Gajahmada Universty Press.

Sudiara, Sukana. (1996). Hygienis Sanitasi dan Keselamatan Kerja. Bali: STP Nusa Dua Bali Press.

Sutanto, E. (2009). Pelatihan Dasar - Dasar Keamanan Air Bagi Pengawas Kolam Renang (Lifeguard) se-DIY . Inotek, 13(2), 121-134

Strauss, Anselm dan Juliet Corbin, (2003). Dasar-dasar Penelitian Kualitatif. Yogyakarta: Pustaka

Umar, Hussein. (2003). Metode Riset Komunikasi Organisasi Jakarta. Jakarta: PT Gramedia Pustaka Utama

Usman, Nurdin. (2002). Konteks Implementasi Berbasis Kurikulum. Jakarta: PT. Raja Grafindo Persada.

Buku

Pedoman

Balawista.(http://balawistabadung.com/information. html), diakses 6 juni 2014 beberapa balawista yang bertugas sambil menegak minuman keras. Ini sangat beresiko selain bisa membahayakan balawista juga membahayakan wisatawan, meski tujuannya untuk mengeratkan hubungan dengan wisatwan.

Saran untuk pihak management balawista diharapkan melakukan pembinaan bagi anggotanya yang melakukan kesalahan dalam melakukan tugasnya. Pembinaan ini diharapkan dapat meningkatkan etos kerja mereka di lapangan. 